\title{
USO DO ÍNDICE LIX NA PREVISÃO DE LIXIVIAÇÃO DOS PESTICIDAS METOLACLORO, ENDOSSULFAM, CLORPIRIFÓS, CARBENDAZIM E DIUROM
}

\author{
ELESSANDRA MARIOT* \\ OSCARLINA LÚCIA DOS SANTOS WEBER** \\ CLÁUDIO APARECIDO SPADOTTO*** \\ ELIANA FREIRE GASPAR DE CARVALHO DORES ${ }^{\star \star \star *}$
}

\begin{abstract}
O objetivo deste estudo foi verificar o potencial do índice LIX na previsão da lixiviação dos agrotóxicos metolacloro, endossulfam, clorpirifós, carbendazim e diurom. Para tanto, coletaram-se amostras de solo, deformada e indeformada, de LATOSSOLO AMARELO distrófico típico, cultivado com algodão do município de Primavera do Leste (MT), nos horizontes Ap (0-20 cm), A/B (20-40 cm) e Bw1 (40$92 \mathrm{~cm})$. Efetuou-se a simulação da lixiviação em laboratório, sendo determinados o coeficiente de sorção e os atributos físico-químicos do solo diretamente relacionados à lixiviação de pesticidas. Para a previsão do potencial de lixiviação, utilizouse o índice LIX. Os resultados experimentais em condições de laboratório, de forma geral, foram concordantes com os do índice LIX, sendo que os agrotóxicos diurom e metolacloro que apresentaram maior mobilidade nas colunas de solo, também apresentaram maiores valores desse índice. Entretanto, a faixa de classificação do LIX proposta para agrotóxicos lixiviáveis, pelos seus autores, não explicou a alta mobilidade encontrada para 0 metolacloro.
\end{abstract}

PALAVRAS-CHAVE: CONTAMINAÇÃO; ÁGUA SUBTERRÂNEA; SORÇÃO.

* $\quad$ Mestre em Agricultura Tropical, Faculdade de Agronomia e Medicina Veterinária (FAMEV), Universidade Federal de Mato Grosso (UFMT), Cuiabá, MT (e-mail: , jffmariot@yahoo.com.br).

** Professora, FAMEV, Cuiabá, MT (e-mail: oscsanwb@cpd.ufmt.br).

*** Pesquisador, Embrapa Meio Ambiente, Jaguariúna, São Paulo, Brasil (e-mail: spadotto@cnpma.embrapa.br).

*** Professora Adjunta, Departamento de Química, Laboratório de Análises de Resíduos de Biocidas, UFMT, Cuiabá, MT (e-mail:eliana@ufmt.br). 


\section{INTRODUÇÃO}

Os agrotóxicos aplicados na agricultura são distribuídos de maneira diferente no ambiente dependendo das propriedades físico-químicas do produto e forma de uso, bem como das características ambientais. Muitos autores (SILVA e FAY, 1994; MATTOS e SILVA 1999; SPADOTTO et al., 2001; SOUZA, 2005; CARBO et al., 2007) reportaram a dinâmica de agrotóxicos em ambientes temperados, porém poucos estudaram seu comportamento em ambiente tropical. Diversos estudos realizados (DORES e DE-LAMONICA-FREIRE, 1999; MARTINS, 2004; SOUZA, 2005; SPADOTTO, 2001; SPADOTTO, 2002) também identificaram a presença dessas substâncias em águas. DORES, MONNERAT e VECCHIATO (2006) em monitoramento de águas subterrâneas detectaram a presença de alguns herbicidas, mostrando a vulnerabilidade dessas águas à contaminação por tais substâncias. Como a cotonicultura demanda intenso uso de agrotóxicos, essa atividade tem sido considerada como potencialmente poluidora. Entretanto, não existem dados suficientes que permitam a avaliação adequada desse impacto.

A prevenção de contaminações do ambiente envolve o conhecimento detalhado do comportamento e do destino dos agrotóxicos após sua aplicação. O destino dos agrotóxicos no ambiente está diretamente relacionado com suas propriedades físico-químicas, quantidade e frequência de uso, método de aplicação, características bióticas e abióticas do ambiente e condições meteorológicas.

Os mecanismos que determinam a distribuição dos agrotóxicos no ambiente são: a lixiviação, carreamento superficial, volatilização, sorção e degradação. A lixiviação corresponde ao transporte vertical dos agrotóxicos no perfil do solo com a água da chuva ou irrigação que desce pelos poros. É importante mencionar que diversos fatores relacionados ao solo, ao clima e à molécula do agrotóxico influenciam seu transporte no perfil do solo.

Os modelos preditivos do comportamento ambiental dos agrotóxicos têm sido muito úteis para a tomada de decisão sobre o uso dessas substâncias, mas necessitam ser validados regionalmente. Regiões cotonícolas de Mato Grosso, em razão do grande uso de agrotóxicos, constituem áreas prioritárias para esse tipo de estudo.

Objetivou-se com este trabalho verificar o potencial do índice LIX na previsão de lixiviação dos agrotóxicos metolacloro, endossulfam, clorpirifós, carbendazim e diurom, tendo como objetivos específicos (1) simular a lixiviação dessas moléculas em laboratório e (2) determinar seu coeficiente de sorção.

\section{MATERIAL E MÉTODOS}

\subsection{LOCALIZAÇÃO DA ÁREA}

As amostras deformadas e indeformadas de LATOSSOLO AMARELO distrófico típico foram coletadas próximo à área de plantio de algodão, na micro-bacia do córrego Chico Nunes, município de Dom Aquino - MT (Figura 1), localizada nas coordenadas de $15^{\circ} 25^{\prime}$ de latitude Sul e $54^{\circ} 32^{\prime}$ de longitude Oeste. Essa área foi escolhida para o estudo por apresentar solos característicos da região e por ser cultivada com algodão próximo de curso d'água, representando risco potencial de contaminação de águas superficiais e subterrâneas. 


\section{FIGURA 1 - LOCALIZAÇÃO GEOGRÁFICA DO MUNICÍPIO DE DOM AQUINOI MT}

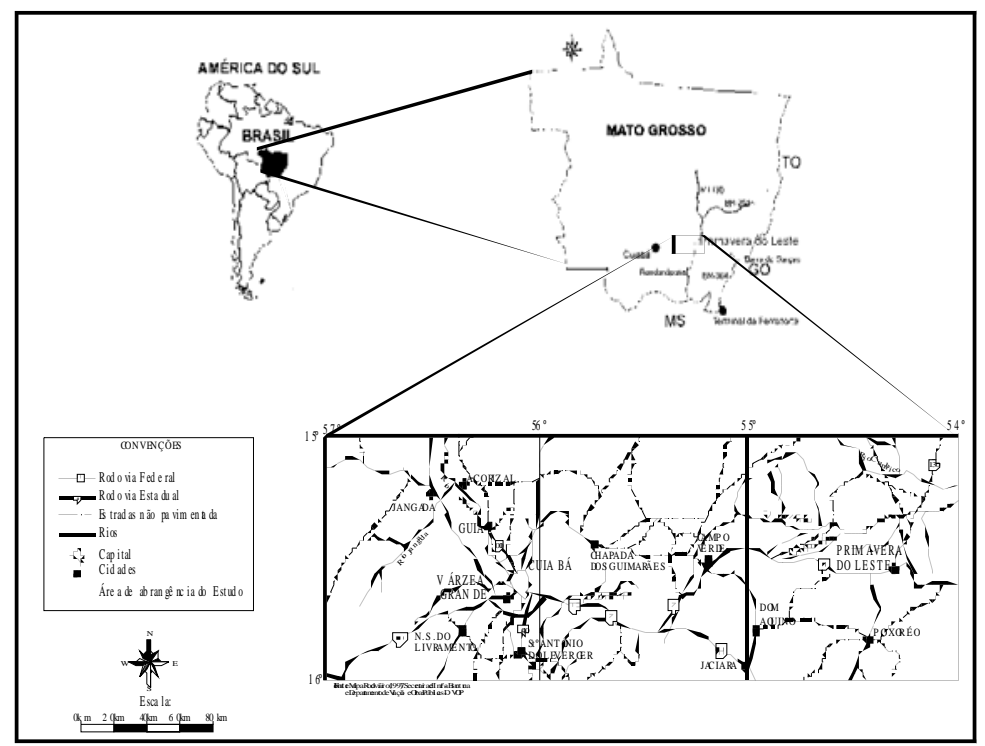

\subsection{COLETA DO SOLO}

Amostras de solo deformadas nos horizontes $\mathrm{Ap}, \mathrm{B} / \mathrm{Ae} B \mathrm{w}_{1}$, correspondentes às respectivas profundidades de $0-30,30-42$ e $42-83 \mathrm{~cm}$ foram coletadas para o ensaio de sorção e de caracterização química (carbono orgânico total) e física (granulometria), segundo métodos da EMBRAPA (1997). A caracterização do solo foi previamente realizada por DORES et al. (2005). Os teores de carbono orgânico total (COT) que encontraram para os horizontes Ap, A/B e Bw1 foram 1,56\%; 1,47\% e 0,99\%, respectivamente. Para a granulometria obtiveram: $A p$ (argila $=631 \mathrm{~g} \mathrm{~kg}^{-1}$, silte $=38 \mathrm{~g} \mathrm{~kg}^{-1}$ e areia $\left.=331 \mathrm{~g} \mathrm{~kg}^{-1}\right) ; \mathrm{A} / \mathrm{B}\left(\right.$ argila $=698 \mathrm{~g} \mathrm{~kg}^{-1}$, silte $=30 \mathrm{~g} \mathrm{~kg}^{-1} \mathrm{e}$ areia $\left.=272 \mathrm{~g} \mathrm{~kg}^{-1}\right)$; $\mathrm{Bw}_{1}\left(\right.$ argila $=631 \mathrm{~g} \mathrm{~kg}^{-1}$, silte $=24 \mathrm{~g} \mathrm{~kg}^{-1}$ e areia $\left.=346 \mathrm{~g} \mathrm{~kg}^{-1}\right)$.

As propriedades físico-químicas ultilizadas no índice LIX para determinação do potencial de lixiviação dos pesticidas são: coeficiente linear de sorção $(K d)$, Coeficiente de partição ao carbono orgânico (Koc), meia-vida $\left(t_{1 / 2}\right)$ e Carbono orgânico total (COT) em porcentagem. Os valores de Koc para o carbendazim e diurom foram obtidos por CARBO et al. (2007) e os agrotóxicos clorpirifós, isômeros alfa e beta do endossulfam e metolacloro tiveram seus coeficientes de sorção determinados no presente estudo.

O ensaio de sorção do endossulfam, clorpirifós e metolacloro seguiu o método proposto por SOUZA, BOEIRA e GOMES (2000). A quantificação dos dois primeiros agrotóxicos na solução em equilíbrio com o solo ocorreu por Cromatografia a Gás/ Espestrometria de Massa enquanto que o terceiro foi quantificado em cromatógrafo a Líquido de Alta Eficiência com detector de ultravioleta com arranjos de diodos (CLAE/DAD).

\subsection{ENSAIO DE LIXIVIAÇÃO EM LABORATÓRIO}

SOUZA (2005) simulou, em laboratório, a lixiviação dos pesticidas em coluna de solo indeformado coletado em coluna de policloreto de vinila (PVC) com $50 \mathrm{~cm}$ de altura e 
$15 \mathrm{~cm}$ de diâmetro e determinou os agrotóxicos tanto na água percolada quanto nas camadas do solo. As quantidades dos agrotóxicos que foram aplicadas nas colunas basearam-se na dosagem por hectare utilizada pelos produtores de algodão e a concentração do ingrediente ativo nos produtos comerciais. Multiplicando-se a dosagem pela concentração do produto comercial obteve-se a quantidade de ingrediente ativo por hectare. Então, multiplicou-se a quantidade de ingrediente ativo por metro quadrado pela área da coluna (As $=0,018 \mathrm{~m}^{2}$ ), obtendo-se, assim, a quantidade de ingrediente ativo a ser aplicado.

As soluções estoque foram preparadas mediante diluição de $50 \mu \mathrm{L}$ do produto comercial em $100 \mathrm{~mL}$ de água deionizada. As quantidades calculadas da solução estoque para aplicação foram de: 3,536 mL de carbendazim, $5,3 \mathrm{~mL}$ de clorpirifos, 14,136 mL de diurom, $8,84 \mathrm{~mL}$ de endossulfam e $8,84 \mathrm{~mL}$ de metolacloro.

\subsection{TESTE DE PERCOLAÇÃO}

Utilizaram-se seis tubos de PVC com amostra indeformada, devidamente acondicionados, os quais foram colocados em recipiente com água para saturar o solo por capilaridade (deixando-os mais ou menos cinco centímetros fora da água). Os agrotóxicos foram aplicados nas quantidades citadas e após 30 min colocou-se camada de lã de vidro sobre a coluna. A primeira chuva de $200 \mathrm{~mm}$ por 24 horas foi simulada. Após 24 horas de repouso, simulou-se a segunda chuva de $200 \mathrm{~mm}$ por mais 24 horas. Aágua percolada foi coletada num intervalo de 12 em 12 horas e mantida em refrigerador até sua extração e análise. Após o final da percolação, o solo foi seccionado de 10 em $10 \mathrm{~cm}$ e os resíduos dos agrotóxicos analisados nas águas coletadas e nas camadas do solo. Os agrotóxicos clorpirifós, endossulfam e metolacloro foram analisados por Cromatografia a Gás com detecção por Espectrometria de Massa (CG/EM) e para os agrotóxicos carbendazim e diurom por Cromatografia a Líquido com detector de ultravioleta com arranjo de diodos (CLAE/DAD).

\subsection{CÁLCULO DO ÍNDICE LIX}

Existem vários índices de previsão de lixiviação, dentre os quais se pode destacar GUS, CDFA, AF e RF, LIX. No presente trabalho, optou-se pelo índice de lixiviação LIX (equação 1), proposto por SPADOTTO (2002), o qual difere do GUS por não gerar valores negativos, facilitando a interpretação dos resultados.

$$
\text { LIX }=\exp (-\mathrm{k} \cdot \mathrm{Koc})
$$

Em que:

$\mathrm{k}=$ constante de primeira ordem de degradação do pesticida $\left(\right.$ dia $\left.^{-1}\right)$, e Koc $=$ coeficiente de sorção de carbono orgânico do agrotóxico ( $\mathrm{mL} \mathrm{g}^{-1}$ C.O.).

O índice LIX varia entre zero e um, representando, respectivamente, o mínimo e o máximo potencial de lixiviação.

O índice LIX, usado para avaliar o potencial de lixiviação de compostos químicos, pode ser extrapolado para ambientes semelhantes, mas não para simular o transporte de agrotóxicos em dada situação de campo. 


\section{RESULTADOS E DISCUSSÃO}

\subsection{SIMULAÇÃO DA LIXIVIAÇÃO EM LABORATÓRIO}

O estudo de lixiviação realizado por SOUZA (2005) mostrou que o clorpirifós não foi detectado nas amostras de água percolada, enquanto o metolacloro foi detectado em todas as amostras de água. A maior quantidade dessa molécula ocorreu nas últimas 12 horas de chuva, tendo sido percolado de 1,2 a 5,9\% do total adicionado. Esse tipo de movimentação é controlado pela adsorção ao solo dos agrotóxicos.

Alfa endossulfam, beta endossulfam e sulfato de endossulfam não foram detectados nas águas percoladas. Alfa e beta endossulfam foram detectados na primeira camada do solo, sendo o beta também detectado na segunda camada de apenas uma coluna. Já o sulfato de endossulfam estava presente nas duas primeiras camadas de todas as colunas e em apenas uma coluna na terceira e quinta camadas. Isto demonstra que o sulfato de endossulfam oferece maior potencial de contaminação das águas subterrâneas quando comparado ao seu composto original, mas de forma lenta devido à sua baixa movimentação. O alfa endossulfam apareceu apenas em três colunas e somente na primeira camada, provavelmente por ser mais facilmente degradado do que o isômero beta (ATSDR, 2000).

O fato de o endossulfam não ser detectado nas águas percoladas e de ter sido encontrado somente na primeira camada de solo sugere seu baixo potencial de contaminação de águas subterrâneas em condições ambientais similares à estudada concordando com PIVATTO (2004).

Quanto ao solo, segundo SOUZA (2005) o alfa e o beta endossulfam foram detectados na primeira camada e o beta também foi detectado na segunda camada de apenas uma coluna. Já o sulfato de endossulfam se apresentou nas duas primeiras camadas de todas as colunas e em apenas uma coluna também na terceira e quinta camadas. Isto demonstra alto potencial de contaminação das águas subterrâneas do sulfato de endossulfam quando comparado ao seu composto original, mas de forma lenta devido à sua baixa movimentação.

Conforme MARTINS (2004), o clorpirifós, devido ao alto coeficiente de sorção, está classificado como inseticida com baixo potencial de contaminação de águas subterrâneas quando aplicado em solos com características semelhantes a dos utilizados neste estudo. SOUZA (2005) concorda dizendo que o clorpirifós foi detectado na primeira camada de todas as colunas evidenciando pouca mobilidade nesse tipo de solo.

O metolacloro foi o produto que apresentou maior mobilidade, sendo encontrado em todas as camadas de todas as colunas de solo e também em todas as águas percoladas. DORES et al. (2008) encontraram o metolacloro, dentre outras substâncias, nas águas subterrâneas da região do presente estudo, evidenciando a grande possibilidade de contaminação dessas águas por metolacloro.

O metolacloro, assim como os demais agrotóxicos estudados, foi detectado em maior concentração nos primeiros $10 \mathrm{~cm}$ que contém maior teor de matéria orgânica, mostrando sua importância na retenção dos agrotóxicos.

O diurom não apresentou elevada mobilidade, sendo detectado apenas nas primeira e segunda camadas de solo de quase todas as colunas. Entretanto, mostrou potencial de lixiviação maior do que o carbendazim (detectado somente na primeira camada). Ambos não foram detectados na água percolada. 
Grandes variações foram observadas entre as colunas, tanto na concentração dos agrotóxicos detectados na água percolada quanto nas camadas de solo. Essa variabilidade elevada deve-se, provavelmente, à compactação do solo (sua densidade variou de 2,53 a $3,25 \mathrm{~g} \mathrm{~cm}^{-3}$ ), à existência de resíduos no solo e à variabilidade natural das propriedades do solo.

O Departamento de Recursos Naturais de lowa encontrou 2,4-D, atrazine, carbofuran e metolacloro em águas subsuperficiais, enquanto no programa de monitoramento de Recursos Naturais do Departamento de Wisconsin foram detectados 2,4-D, aldicarb, atrazina, carbofuran, dicamba, metolacloro e simazine em poços das áreas com problemas de contaminação. Nesse mesmo tipo de programa, do Departamento de Minnesota, foram encontrados 2,4-D, aldicarb, atrazina, dicamba, metolacloro, picloram e simazina em poços de áreas com lençol freático sujeito à contaminação (SPADOTTO, 2001).

\section{2 ÍNDICE LIX OBTIDO PARA OS AGROTÓXICOS ESTUDADOS}

Na Tabela 1 são apresentados os resultados obtidos pelo índice LIX. Comparandoos com os resultados da simulação da lixiviação no laboratório, observa-se que o metolacloro apresentou maior mobilidade nas colunas e também maiores valores de LIX, inclusive na camada superficial.

\section{TABELA 1 - ALGUNS PARÂMETROS FÍSICO-QUÍMICOS E OS ÍNDICES LIX DOS PESTICIDAS ESTUDADOS}

\begin{tabular}{|c|c|c|c|c|c|c|c|}
\hline Pesticidas & Horizontes & $\mathrm{Kd}$ & Koc & $\mathrm{T} 1 / 2^{1}$ & $\mathbf{K}$ & C $0 \%^{2}$ & LIX \\
\hline \multirow[t]{3}{*}{ Alfa endossulfam } & $A p$ & 288 & 18.462 & 43 & 0,01612 & 1,56 & 0 \\
\hline & $A / B$ & 209 & 14.218 & 43 & 0,01612 & 1,47 & 0 \\
\hline & Bw1 & 44 & 4.444 & 43 & 0,01612 & 0,99 & $7,86 \mathrm{E}-32$ \\
\hline \multirow[t]{3}{*}{ Beta endossulfam } & Ap & 405 & 25.962 & 128 & 0,00541 & 1,56 & $9,03 E-62$ \\
\hline & $A / B$ & 230 & 15.646 & 128 & 0,00541 & 1,47 & $1,63 \mathrm{E}-37$ \\
\hline & Bw1 & 42 & 4.242 & 128 & 0,00541 & 0,99 & 1,06E-10 \\
\hline \multirow{3}{*}{ Carbendazim } & Ap & 27 & 1.731 & 128 & 0,00541 & 1,56 & $8,52 \mathrm{E}-05$ \\
\hline & $A / B$ & 15 & 1.020 & 128 & 0,00541 & 1,47 & 0,004 \\
\hline & Bw1 & 15,5 & 1.566 & 128 & 0,00541 & 0,99 & 0,00021 \\
\hline \multirow{3}{*}{ Clorpirifós } & Ap & 45 & 2.885 & 14,5 & 0,04779 & 1,56 & $1,31 E-60$ \\
\hline & $A / B$ & 23 & 1.565 & 14,5 & 0,04779 & 1,47 & $3,34 \mathrm{E}-33$ \\
\hline & Bw1 & 17 & 1.717 & 14,5 & 0,04779 & 0,99 & $2,30 \mathrm{E}-36$ \\
\hline \multirow[t]{3}{*}{ Diurom } & Ap & 14 & 897 & 42 & 0,01650 & 1,56 & $3,69 \mathrm{E}-07$ \\
\hline & $A / B$ & 2,6 & 177 & 42 & 0,01650 & 1,47 & 0,0539 \\
\hline & Bw1 & 1,4 & 141 & 42 & 0,01650 & 0,99 & 0,0976 \\
\hline \multirow[t]{3}{*}{ Metolacloro } & Ap & 3 & 192 & 34 & 0,02038 & 1,56 & 0,0198 \\
\hline & $A / B$ & 3,9 & 265 & 34 & 0,02038 & 1,47 & 0,0045 \\
\hline & Bw1 & 1,7 & 172 & 34 & 0,02038 & 0,99 & 0,0302 \\
\hline
\end{tabular}

${ }^{1}$ Tempo de meia-vida (MARTINS, 2006), ${ }^{2} \mathrm{C}$ O = Carbono orgânico.

Os agrotóxicos com menor mobilidade nas colunas, alfa e beta endossulfam, cabendazim e clorpirifós forneceram valores de LIX menores do que $10^{-5}$. Por outro lado, 0 diurom que lixiviou até a segunda camada do solo revelou pequeno valor de LIX na camada superficial, mas valores elevados nas camadas mais profundas. 
O carbendazim e o clorpirifós apresentaram baixo potencial de lixiviação, segundo o índice aplicado, e foram encontrados nos primeiros dez centímetros nas colunas, reforçando suas características de baixa mobilidade observadas por MARTINS (2006).

O diurom foi detectado nos primeiros $20 \mathrm{~cm}$ da coluna o que resulta em correlação positiva com os valores de LIX (baixo potencial de lixiviação), especialmente no horizonte Ap. Sabe-se que apesar desse agrotóxico ficar mais retido no horizonte Ap, ele também tem maior potencial à lixiviação, confirmando os resultados de SPADOTTO (2002) que encontrou LIX de 0,02 para o diurom.

DORES et al. (2005), estudando a degradação do metolacloro em Latossolo no município de Dom Aquino obtiveram valor de meia-vida de 91 dias em solo seco e 35 dias em solo úmido.

SPADOTTO (2002), estudando o potencial de vários agrotóxicos, encontrou valor de LIX igual a 0,21 para o metolacloro, o que o classifica como potencialmente lixiviável. De forma diferente do ocorrido neste trabalho, tal índice foi calculado com dados de Koc e tempo de meia-vida obtidos da literatura.

Conforme SPADOTTO (2002), o índice LIX parece constituir poderosa ferramenta para identificar como não lixiviáveis aqueles agrotóxicos com valores de LIX igual a zero e como lixiviáveis os agrotóxicos com LIX maior ou igual a 0,1, sendo que os valores de LIX entre 0 e 0,1 são caracterizados como zona de transição. Pela simplicidade do índice LIX não se pode pretender que ele seja absoluto, o que certamente não invalida o seu uso como indicador do potencial de lixiviação, pois vários são os fatores que interferem nesse potencial.

\section{CONCLUSÃO}

Dentre os agrotóxicos estudados, o diurom e o metolacloro foram os que mostraram maior potencial de lixiviação no ensaio em laboratório e pelo índice LIX. Entretanto, nenhum dos dois agrotóxicos obteve índices maiores do que 0,1, sendo considerados pela classificação proposta no LIX como pertencendo à zona de transição. Pelo ensaio de laboratório, o diurom movimentou-se nas camadas de solo não tendo sido encontrado na água de percolação, confirmando essa classificação. Por outro lado, o metolacloro comportou-se como altamente móvel tendo sido detectado em todas as camadas de solo e na água percolada, indicando elevado potencial de lixiviação.

Cabe ressaltar que a coluna de lixiviação em laboratório pode produzir caminhos preferenciais nas paredes da coluna como induzir a formação desses caminhos durante a coleta da coluna indeformada. Além disso, os Latossolos comportam-se como areia diante da formação de microagregados, o que também contribui para a alta infiltração de água e percolados. Dessa forma, caberia a rediscussão das faixas de LIX nas quais os agrotóxicos deveriam ser classificados como lixiviáveis.

\section{ABSTRACT}

THE USAGE OF LIX INDEX AS A SCREENING METHOD TO ASSESS LEACHING POTENTIAL OF METOLACHLOR, ENDOSULFAN, CHLORPYRIPHOS, CARBENDAZIN AND DIURON

This study aimed to verify the application of the LIX index as a leaching screening method for the agrotoxic metolachlor, endosulfan, chlorpyriphos, carbendazin and diuron. For this, soil samples were collected, deformed and not deformed, from an Yellow Latosol cultivated with cotton from the municipality of Primavera 
do Leste, MT (Brasil), in the horizons Ap ( 0-20 cm), A/B $(20-40 \mathrm{~cm})$ and Bw1 $(40-92 \mathrm{~cm})$. A leaching simulation was done in the laboratory; and sorption coefficient and soil physical-chemical attributes directly related to agrotoxic leaching, were determined. For assessment of the leaching potential it was used the LIX index. In general, the experimental results in laboratory were in agreement with the LIX index results, whereas diuron and metolachlor which have higher mobilitly in the soil columns, also presented higher LIX value. However, the classification range purposed by the LIX authors did not explain the high mobility found for metolachlor in the laboratory simulation.

KEY-WORDS: CONTAMINATION; UNDERGROUND WATER; SORPTION.

\section{REFERÊNCIAS}

1 ATSDR. Agency for Toxic Substances and Diseases Registry. U. S. Department of Health and Human Services. Public Health Service. Toxilogical profile for endosulfan. 2000. p. 195. Disponível em: http://www.atsdr.cdc.gov/ toxprofiles/tp41.pdf. Acesso em: 20/02/08b.

2 CARBO, L.; MARTINS, E. de L.; DORES, E. F. G. C.; SPADOTTO, C. A.; WEBER, O.L.S.; FREIRE, E.M.L. Acetamiprid, carbendazim, diuron and thiamethoxam sorption in two Brazilian Tropical Soils. Journal of Environmental Science and Health, Part B, Pesticides, Food Contaminants, and Agricultural Wastes, v. 42, p. $449-507,2007$

3 DORES, E. F. G. C.; DE-LAMONICA-FREIRE, E. M. Contaminação do ambiente aquático por pesticidas: vias de contaminação e dinâmica dos pesticidas no ambiente aquático. Pesticidas: r. ecotoxicol. e meio ambiente, Curitiba, v. 9, p.1-18, 1999.

4 DORES, E. F. G. C.; CARBO, L.; RIBEIRO, M .L.; DE-LAMONICA-FREIRE, E.M. Pesticide levels in ground and surface waters of Primavera do Leste region, Mato Grosso, Brazil. Journal of Chromatographic Science, 2008, no prelo.

5 DORES, E. F. G. C.; MONNERAT, R. G.; VECCHIATO, A.B. Algodão e proteção ambiental In: ALGODÃO: pesquisas e resultados para o campo. Cuiabá: Facual, 2006. v. 2, p. 360-390.

6 DORES, E. F. G. C.; WEBER, O. L. S.; VECCHIATO, A.B.; SHIRAIWA, S.; SALOMÁO, F. X. T.; CUTRIM, A.; GUIMARÃES, S.C.; RIEDER, A.; PINTO, A. A.; PEREIRA, M.J.; NASCIMENTO, A.L. Estudo da contaminação de biocidas no ambiente e seu monitoramento em águas superficiais, subterrâneas e pluviais em regiões cotonícolas do Estado de Mato Grosso. Cuiabá: Universidade Federal de Mato Grosso, 2005. (Relatório final, fase 2).

7 EMBRAPA. Empresa Brasileira de Pesquisa Agropecuária. 2 ed. Manual de métodos de análise de solo. Rio de Janeiro: Centro Nacional de Pesquisa de Solos, 1997. 212 p.

8 MARTINS, E. L. Interações sortivas do pesticida clorpirifós em Gleissolo e Latossolo amarelo. Cuiabá, 2004. 50 p. Monografia (conclusão de curso de Agronomia), Universidade Federal de Mato Grosso.

9 MARTINS, E.L. Previsão da lixiviação de pesticidas utilizados na cultura do algodão em Mato Grosso. Cuiabá: Universidade Federal de Mato Grosso, 2006. 82 p.

10 MATTOS, L.M.; SILVA, E.F. Influência das propriedades de solos e pesticidas no potencial de contaminação dos solos e águas subterrâneas. Pesticidas: revista de ecotoxicologia e meio ambiente, Curitiba v. 9, p. 103-124, 1999.

11 PIVATTO, M. Estudo da sorção do inseticida endosulfan e seu metabólito sulfato de endosulfan em solos do tipo Glei Húmico e Latossolo Vermelho Amarelo. Cuiabá, 2004. 53 p. Monografia (conclusão do curso de Agronomia), Universidade Federal de Mato Grosso.

12 SILVA, C.M.M.; FAY, E.F. (Ed.). Agrotóxicos e meio ambiente. Brasília, DF: Embrapa Informação Tecnológica, 2004. $400 \mathrm{p}$.

13 SOUZA, M.D.; BOEIRA, R.C.; GOMES, M.A.F. Adsorção e dessorção de diurom em solos tropicais. Pesticidas: revista de ecotoxicologia e meio ambiente, Curitiba v. 10, p. 113-124, 2000.

14 SOUZA, L. Simulação em laboratório da lixiviação de biocidas usados na cultura de algodão em Latossolo Amarelo do município Dom Aquino, Mato Grosso. Cuiabá, 2005. 46 p. Monografia (conclusão de curso de Agronomia), Universidade Federal do Mato Grosso.

15 SPADOTTO, C. A. Screening method for assessing pesticide leaching potential. Pesticidas: revista de ecotoxicologia e meio ambiente, Curitiba, v. 12, p. 69-78, jan./dez. 2002.

16 SPADOTTO, C. A. Relatório técnico sobre a conferência internacional organizada pela Embrapa Meio Ambiente. Campinas: EMBRAPA, 2001. 